\title{
MODEL STRATEGI KOPERASI "NIRA SATRIA" DALAM MENDUKUNG AGROINDUSTRI GULA KRISTAL SKALA RUMAH TANGGA
}

\author{
Sulistyani Budiningsih dan Ani Kusbandiyah \\ Fakultas Pertanian dan Fakultas Ekonomi Univ. Muhammadiyah Purwokerto \\ Jl Raya Dukuhwaluh PO Box 202 Purwokerto
}

\begin{abstract}
ABSTRAK
Tujuan penelitian adalah (1) Menganalisis faktor - faktor internal dan eksternal bagi kelembagaan Koperasi Nira Satria di Kecamatan Cilongok Kabupaten Banyumas, (2) Merumuskan model strategi Koperasi Nira Satria dalam mendukung agroindustri gula kristal skala rumah tangga di Kecamatan Cilongok Kabupaten Banyumas. Penelitian berupa penelitian deskriptif kualitatif yang dilakukan melalui kegiatan observasi dan wawancara secara mendalam dengan informan kunci yang dianggap mengetahui secara detail tentang faktor internal dan eksternal bagi kelembagaan Koperasi Nira Satria, selain itu guna mendapatkan informasi yang akurat dilakukan FGD (Focus Discusion Group). Lokasi penelitian ditetapkan secara sengaja (Purposive Sampling) di Kecamatan Cilongok. Sampel penelitian mencakup responden pengrajin gula kristal sekaligus anggota koperasi sejumlah 20 pengrajin dan informan kunci meliputi Manager, Ketua dan Pengurus Koperasi Nira Satria ditambah PPL. Jenis data berupa data primer dan sekunder. Selanjutnya data dianalisis dengan teknik analisis deskriptif kualitatif dan kuantitatif sederhana. Hasil penelitian menunjukkan bahwa hasil evaluasi faktor - faktor internal menunjukkan nilai skor untuk kekuatan (Strengths) sebesar 1,925 dan skor kelemahan (Weaknesses) sebesar 0,805. Dengan demikian nilai skor pada sumbu horisontal (sumbu X) adalah : 1,925 - 0,805 = 1,120. Sementara faktor eksternal skor untuk peluang (Opportunities) sebesar 1,620 dan jumlah skor untuk ancaman (Threaths) sebesar 0,533. Nilai skor sumbu vertikal (sumbu Y) adalah sebesar 1,620 - 0,533 = 1,087. Dengan demikian strategi kelembagaan Koperasi Nira Satria pengajin gula kristal di Kecamatan Cilongok berada pada posisi kuadran I, sebagai Strategi Agresif yaitu strategi pengembangan kelembagaan Koperasi Nira Satria pengrajin gula kristal dilakukan dengan cara memaksimalkan potensi atau kekuatan yang dimiliki guna meraih peluang secara optimal yang dilakukan dengan menciptakan hubungan yang kondusif, demokratis dan kekeluargaan antara pengrajin, manager beserta pengurus koperasi guna mendukung peningkatan kuantitas dan kualitas produk gula kristal sehingga dapat memenuhi permintaan pasar nasional dan internasional secara kontinue (S3,4 ; O1,2,3). Memaksimalkan semua unit usaha yang dikelola Koperasi Nira Satria supaya dapat berkembang pesat dengan memanfaatkan teknologi SIM (S5;O6)
\end{abstract}

Kata Kunci : Model, Koperasi, Gula Kristal, Skala Rumah Tangga

\section{PENDAHULUAN}

Subsektor perkebunan merupakan salah satu dari satu subsektor pertanian yang secara tradisional telah mampu mengasilkan devisa bagi negara melalui ekspor hasil perkebunan yang sebagian besar merupakan usaha perkebunan rakyat, perkebunan milik pemerintah dan swasta. Upaya peningkatan nilai tambah produk pertanian termasuk hasil perkebunan dapat dilakukan dengan agroindustri. Agroindustri dapat diandalkan menjadi leading sector atau sektor yang memimpin dalam perekonomian Indonesia, karena agroindustri (a) Memiliki pangsa pasar yang besar dalam perekonomian secara keseluruhan sehingga kemajuan yang dicapai 


\section{Budiningsih dan Kusbandiyah' MODEL STRATEGI KOPERASI}

dapat menarik pertumbuhan perekonomian secara total, (b) Memiliki pertumbuhan dan nilai tambah yang relatif tinggi, (c) Memiliki keterkaitan ke depan dan ke belakang yang cukup besar sehingga mampu menarik pertumbuhan banyak sektor lain, (d) Keragaman dan performannya berbasis sumber daya domestik sehingga efektif dalam membangun daerah yang kuat dan fleksibel terhadap goncangan eksternal.

Salah satu agroindustri dari pohon kelapa berupa olahan nira menjadi produk gula kelapa dapat memberikan keuntungan finansial. Kecamatan Cilongok sebagai sentra agroindustri gula kelapa yang termasuk dalam wilayah Kabupaten Banyumas. Agroindustri gula kelapa di Kecamatan Cilongok sebagian besar merupakan agroindustri warisan dari turun temurun orang tua yang dikelola dalam skala rumah tangga. Lebih lanjut dijelaskan bersumber Monografi Kecamatan (2014) bahwa gula kelapa merupakan komoditas unggulan bagi masyarakat di Kecamatan Cilongok Kabupaten Banyumas, karena kemampuan potensi komoditas tersebut mampu memacu berkembangnya kegiatan agribisnis yang sebagian besar penduduk bermata pencaharian sebagai pengrajin gula kelapa.

Kondisi masyarakat pada saat ini telah mengalami perubahan pola konsumsi masyarakat sehingga produk gula kelapa cetak mengalami perubahan bentuk diolah menjadi gula kelapa kristal organik/semut. Pada saat ini terdapat 31.416 unit usaha gula kelapa dengan volume produksi telah mampu mencapai $72.109,19$ ton per tahun yang tersebar di berbagai wilayah kecamatan Kabupaten Banyumas. Produk gula kristal/semut yang dihasilkan di Kecamatan Cilongok telah mampu menembus pasaran domestik dan pasar luar negeri melalui peran kelembagaan Koperasi Nira Satria yang berdomisili di Kecamatan Cilongok. Terbentuknya Koperasi Nira Satria mendapat dukungan para pengrajin skala rumah tangga dan sampai saat ini telah memiliki anggota sebanyak 230 orang. Melalui kelembagaan Koperasi Nira Satria ini para pengrajin akan mampu mencapai keberhasilan pengembangan agroindustri gula kristal skala rumah tangga. Oleh karena itu agroindustri gula kristal skala rumah tangga harus mampu merancang model kelembagaan yang paling cocok untuk pengembangan melalui kelembagaan Koperasi Nira Satria. Bertolak dari hal tersebut perlu dilakukan penelitian model strategi pada kelembagaan Koperasi Nira Satria dalam mendukung agroindustri gula kristal skala rumah tangga .Berdasarkan latar belakang masalah diatas, maka tujuan penelitian ini adalah Menganalisis faktor faktor internal dan eksternal bagi kelembagaan Koperasi Nira Satria di Kecamatan Cilongok Kabupaten Banyumas dan merumuskan model strategi Koperasi Nira Satria dalam mendukung agroindustri gula kristal skala rumah tangga di Kecamatan Cilongok Kabupaten Banyumas. 


\section{METODE PENELITIAN}

\section{Lokasi Penelitian}

Penelitian dilaksanakan di Kecamatan

Cilongok Kabupaten Banyumas yang merupakan daerah penghasil gula kristal paling dominan dibanding dengan daerah kecamatan lainnya.

\section{Metode Penentuan Sampel}

Penentuan informan kunci dipilih secara sengaja (Purposive), yang terdiri dari ketua, sekretaris dan lima pengurus Koperasi Nira Satria, Petugas Penyuluh Lapangan (PPL) . Sampel pengrajin dipilih secara sengaja (Purposive) sebanyak 20 pengrajin gula kristal yang telah menjadi anggota Koperasi Nira Satria.

\section{Jenis dan Sumber Data}

Jenis data yang digunakan meliputi data primer dan sekunder. Pengumpulan data primer dilakukan dengan wawancara mendalam (indepth interview) kepada stakeholder terkait meliputi ketua koperasi, sekretaris koperasi, pengrajin sekaligus anggota koperasi, penyuluh lapang pertanian (PPL). Analisis data sekunder merupakan teknik pengumpulan data yang bersumber dari arsip, dokumen, catatan, buku, jurnal, serta hasil penelitian yang relevan dengan tema penelitian dan berasal dari pemerintahan desa, pemerintahan kecamatan, Desperindagkop Kabupaten Banyumas ataupun lainnya.

\section{Metode Analisis}

Seluruh data yang terkumpul diolah sesuai dengan rancangan metode analisis yang digunakan. Data yang telah terkumpul melalui kegiatan observasi, wawancara konsultatif dan dokumentasi selanjutnya dianalisis dengan teknik analisis kuantitatif sederhana dan deskriptif kualitatif. Keseluruhan data kualitatif dianalisis secara Interactive Model of Analysis (Miles \& Huberman,1991). Analisis terhadap kekuatan kelemahan dan ancaman peluang yang melingkupi kelembagaan Koperasi Nira Satria digunakan analisis SWOT.

\section{HASIL DAN PEMBAHASAN}

Identifikasi Faktor - Faktor Internal pada Kelembagaan Koperasi Nira Satria di Kecamatan Cilongok

Secara lengkap analisis faktor - faktor internal berupa kekuatan dan kelemahan bagi kelembagaan Koperasi Nira Satria di Kecamatan Cilongok Kabupaten Banyumas diuraikan secara rinci pada Tabel 1.

Secara lengkap analisis faktor faktor eksternal berupa peluang dan ancaman bagi Kelembagaan Koperasi Nira Satria di Kecamatan Cilongok Kabupaten Banyumas diuraikan secara rinci pada Tabel 2 . 
Tabel 1. Analisis Faktor - Faktor Internal Kekuatan dan Kelemahan (IFAS)

Koperasi Nira Satria di Kecamatan Cilongok Kabupaten Banyumas

\begin{tabular}{|c|c|c|c|c|}
\hline No & Faktor-Faktor Strategis Internal & Rating & Bobot & $\begin{array}{l}\text { Bobot x } \\
\text { Rating }\end{array}$ \\
\hline \multicolumn{5}{|c|}{ KEKUATAN } \\
\hline 1. & $\begin{array}{l}\text { Koperasi Nira Satria telah berbadan hukum dan } \\
\text { memiliki visi dan misi yang jelas }\end{array}$ & 4 & 0,150 & 0,600 \\
\hline 2. & $\begin{array}{l}\text { Letak kantor koperasi Nira Satria yang cukup } \\
\text { strategis dengan bangunan gedung yang baru }\end{array}$ & 3 & 0,065 & 0,195 \\
\hline 3. & Memiliki struktur organisasi koperasi yang jelas & 4 & 0,100 & 0,400 \\
\hline 4. & $\begin{array}{l}\text { Manager beserta pengurus koperasi Nira Satria } \\
\text { cukup berpengalaman dan bersifat demokratis }\end{array}$ & 3 & 0,050 & 0,150 \\
\hline 5. & $\begin{array}{l}\text { Banyaknya unit usaha yang dikelola koperasi } \\
\text { Nira Satria }\end{array}$ & 3 & 0,040 & 0,120 \\
\hline 6. & $\begin{array}{l}\text { Koperasi Nira Satria telah memanfaatkan } \\
\text { teknologi sistem informasi manajemen dalam } \\
\text { operasional usahanya }\end{array}$ & 3 & 0,015 & 0,045 \\
\hline \multirow[t]{3}{*}{7.} & $\begin{array}{l}\text { Kemampuan produk gula kristal mencapai } \\
\text { jangkauan pemasaran secara nasional dan } \\
\text { internasional }\end{array}$ & 4 & 0,115 & 0,460 \\
\hline & & & & $\mathbf{1 , 9 7 0}$ \\
\hline & \multicolumn{4}{|l|}{ KELEMAHAN } \\
\hline 1. & $\begin{array}{l}\text { Berkurangnya generasi muda penerus bidang } \\
\text { pertanian khususnya profesi pengrajin gula } \\
\text { kristal berbahan baku nira }\end{array}$ & 2 & 0,115 & 0,230 \\
\hline 2. & $\begin{array}{l}\text { Kurangnya sumber sumber permodalan bagi } \\
\text { Koperasi Nira Satria }\end{array}$ & 2 & 0,120 & 0,240 \\
\hline 3. & $\begin{array}{l}\text { Adanya keterbatasan para pengurus Koperasi } \\
\text { Nira Satria dalam memanfaatkan teknologi }\end{array}$ & 2 & 0,080 & 0,160 \\
\hline 4. & $\begin{array}{l}\text { Belum semua unit usaha yang dikelola Koperasi } \\
\text { Nira Satria bisa berkembang dengan pesat }\end{array}$ & 1 & 0,150 & 0,150 \\
\hline & & & & 0,780 \\
\hline & NILAI TOTAL & & 1,000 & 2,750 \\
\hline
\end{tabular}

Sumber : Olahan Data Primer (Th 2015).

Berdasarkan hasil analisis dengan IFAS (Internal Factors Analysis Summary) menunjukkan nilai sebesar 2,730 dan EFAS ( Eksternal Factors Analysis Summary) menunjukkan nilai sebesar 2,635. Berdasarkan hasil analisis faktor internal pada Tabel 1 dan faktor eksternal pada Tabel 2 selanjutnya dapat ditentukan beberapa strategi yang digunakan untuk memecahkan persoalan persoalan yang dihadapi kelembagaan Koperasi Nira Satria di Kecamatan Cilongok Kabupaten Banyumas. Diawali dengan pembuatan Matrik Space Analysis kemudian digunakan sebagai dasar untuk menyusun Matrik SWOT (Tabel 3). 
Tabel 2. Analisis Faktor - Faktor Peluang Dan Ancaman (EFAS) Koperasi Nira Satria di Kecamatan Cilongok Kabupaten Banyumas

\begin{tabular}{|c|c|c|c|c|}
\hline No & Faktor Eksternal & & & \\
\hline & & Rating & Bobot & $\begin{array}{c}\text { Bobot } x \\
\text { Rating }\end{array}$ \\
\hline & \multicolumn{4}{|l|}{ PELUANG } \\
\hline 1. & $\begin{array}{l}\text { Adanya peluang pasar yang prospektif } \\
\text { secara nasional /internasional bagi } \\
\text { produk gula kristal }\end{array}$ & 4 & 0,125 & 0,500 \\
\hline 2. & $\begin{array}{l}\text { Peningkatan konsumsi } \\
\text { terhadap produk gula kristal }\end{array}$ & 3 & 0,075 & 0,225 \\
\hline 3. & $\begin{array}{l}\text { Adanya perubahan gaya hidup secara } \\
\text { sehat di masyarakat }\end{array}$ & 3 & 0,100 & 0,100 \\
\hline 4. & $\begin{array}{l}\text { Pembinaan dan pelatihan oleh pihak } \\
\text { PEMDA, Disperindag dan instansi } \\
\text { terkait kepada pengurus dan anggota } \\
\text { Koperasi Nira Satria }\end{array}$ & 3 & 0,135 & 0,405 \\
\hline 5. & $\begin{array}{lllll}\text { Tersedianya UU No } & 12 & \text { tahun } & 1992 \\
\text { tentang Koperasi }\end{array}$ & 4 & 0,115 & 0,460 \\
\hline \multirow[t]{3}{*}{6.} & $\begin{array}{l}\text { Semakin berkembangnya teknologi } \\
\text { sistem informasi dan manajemen (SIM) }\end{array}$ & 3 & 0,110 & 0,330 \\
\hline & NILAI & & & 2,020 \\
\hline & \multicolumn{4}{|l|}{ ANCAMAN } \\
\hline 1. & $\begin{array}{l}\text { Peran tengkulak yang lebih dominan } \\
\text { dalam penetapan harga dibanding } \\
\text { pengrajin }\end{array}$ & 2 & 0,115 & 0,230 \\
\hline 2. & $\begin{array}{l}\text { Sikap pengrajin yang masih } \\
\text { berhubungan dengan lembaga keuangan } \\
\text { non formal di masyarakat } \\
\text { terjerat sistem ijon }\end{array}$ & 2 & 0,090 & 0,180 \\
\hline 3. & $\begin{array}{l}\text { Masih terbatasnya sarana prasaran pada } \\
\text { sistem informasi manajemen di Koperasi } \\
\text { Nira Satria }\end{array}$ & 1 & 0,126 & 0,126 \\
\hline & & & & $\mathbf{0 , 5 3 6}$ \\
\hline & NILAI TOTAL & & 1,000 & 2,556 \\
\hline
\end{tabular}

Sumber : Olahan Data Primer, 2015 
Tabel 3. Penentuan Strategi Dengan Matrik SWOT Kelembagaan Koperasi Nira Satria Pengrajin Gula Kristal di Wilayah Kecamatan Cilongok Kabupaten Banyumas.

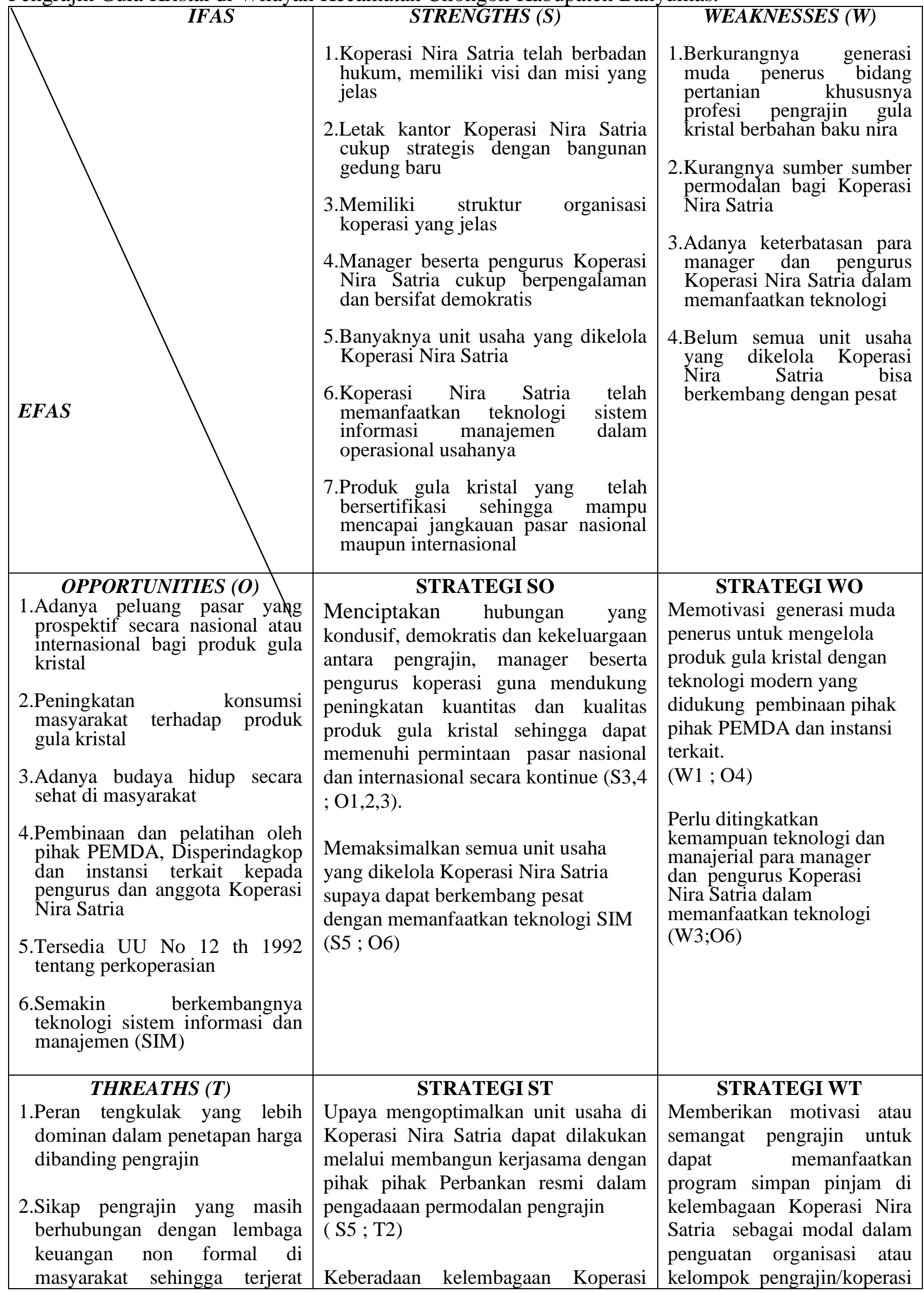




\begin{tabular}{|l|l|l|r|}
\hline sistem ijon & $\begin{array}{l}\text { Nira Satria perlu ditingkatkan } \\
\text { perannya guna memutus hubungan } \\
\text { pengrajin dengan lembaga non formal } \\
\text { di masyarakat }\end{array}$ & $\begin{array}{l}\text { secara optimal guna } \\
\text { meningkatkan posisi tawar } \\
\text { pengrajin gula kristal serta } \\
\text { dapat bersaing secara sehat } \\
\text { (W1; T2) }\end{array}$ \\
$\begin{array}{l}\text { 3.Masih terbatasnya sarana } \\
\text { prasana sistem informasi dan } \\
\text { manajemen di Koperasi Nira } \\
\text { Satria }\end{array}$ & S1,2,3,4; T1,2) & \\
\hline
\end{tabular}

Sumber : Olahan Data Primer (2015)

Matrik Posisi Kelembagaan Koperasi Nira Satria Pengrajin Gula Kristal di Kecamatan Cilongok Kabupaten Banyumas

Berdasarkan hasil evaluasi faktor internal menunjukkan nilai skor untuk kekuatan (Strengths) sebesar 1,925 dan skor kelemahan (Weaknesses) sebesar 0,805. Dengan demikian nilai skor pada sumbu horisontal (sumbu X) adalah :
$1,925-0,805=1,120$. Sementara faktor eksternal skor untuk peluang (Opportunities) sebesar 1,620 dan jumlah skor untuk ancaman (Threaths) sebesar 0,533. Nilai skor untuk sumbu vertikal (sumbu Y) adalah 1,620 $0,533=1,087$

Berdasarkan matrik space analysis dapat dibuat matrik posisi kelembagaan Koperasi Nira Satria pngrajin gula kristal sebagai berikut :

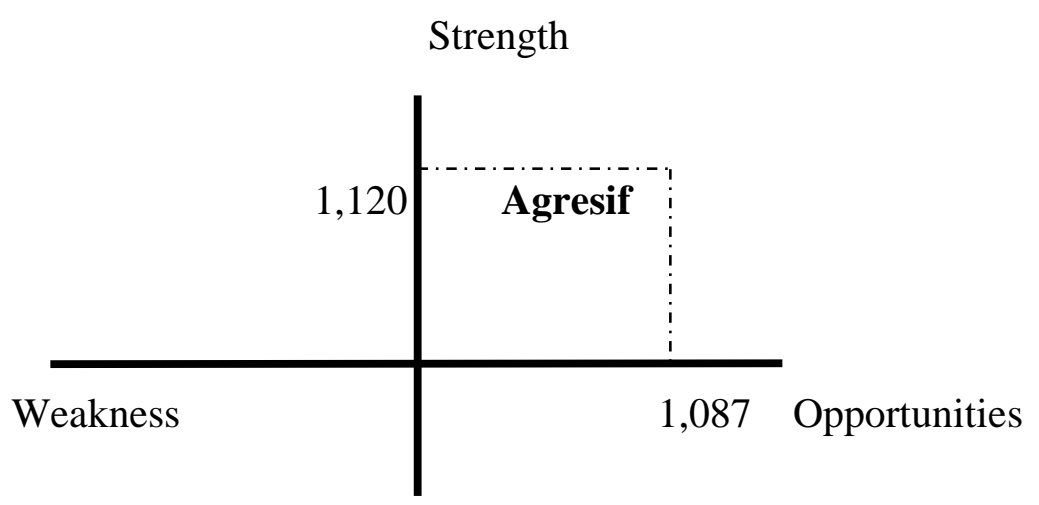

Threath

\section{Gambar 1. Matrik Posisi Pelaku Entrepreneur Pengrajin Gula Kristal di Kecamatan Cilongok Kabupaten Banyumas}

Dengan demikian strategi

kelembagaan Koperasi Nira Satria pengajin

gula kristal di Kecamatan Cilongok berada

pada posisi kuadran I, yang merupakan posisi

sangat menguntungkan karena agroindustri

gula kristal di Kecamatan Cilongok

Kabupaten Banyumas memiliki kekuatan dan peluang yang dapat manfaatkan. Strategi yang harus ditetapkan adalah mendukung kebijakan pertumbuhan agresif (Growth Oriented Strategy). 
B. Model Strategi Koperasi Nira Satria Dalam Mendukung Agroindustri Gula Kristal Skala Rumah Tangga

\begin{tabular}{|l|}
\hline \multicolumn{1}{|c|}{ FAKTOR-FAKTOR INTERNAL } \\
\hline FAKTOR- \\
KEKUATAN : \\
a. Koperasi Nira Satria telah berbadan \\
hukum, memiliki visi dan misi jelas \\
b.Letak kantor Koperasi Nira Satria \\
yang cukup strategis dan bangunan \\
gedung yang baru \\
c.Memiliki struktur organisasi koperasi \\
yang jelas \\
d.Manager beserta pengurus Koperasi \\
Nira Satria cukup berpengalaman \\
bersifat demokratis \\
e.Banyaknya unit usaha yang dikelola \\
Koperasi Nira Satria \\
f.Koperasi Nira Satria telah \\
memanfaatkan teknologi sistem \\
informasi manajemen dalam \\
operasional usahanya \\
g.Produk gula kristal yang telah \\
bersertifikasi sehingga mampu \\
mencapai jangkauan pasar nasional \\
maunun internasional \\
\hline KELEMAHAN : \\
a.Berkurangnya generasi muda penerus \\
bidang pertanian khususnya profesi \\
pengrajin gula kristal \\
b.Kurangnya sumber permodalan bagi \\
Koperasi Nira Satria \\
c.Adanya keterbatasan manager dan \\
para pengurus Koperasi Nira Satria \\
dalam memanfaatkan teknologi \\
sistem informasi manajemen (SIM) \\
d.Belum semua unit usaha yang \\
dikelola Koperasi Nira Satria bisa \\
berkembang dengan pesat \\
\hline
\end{tabular}

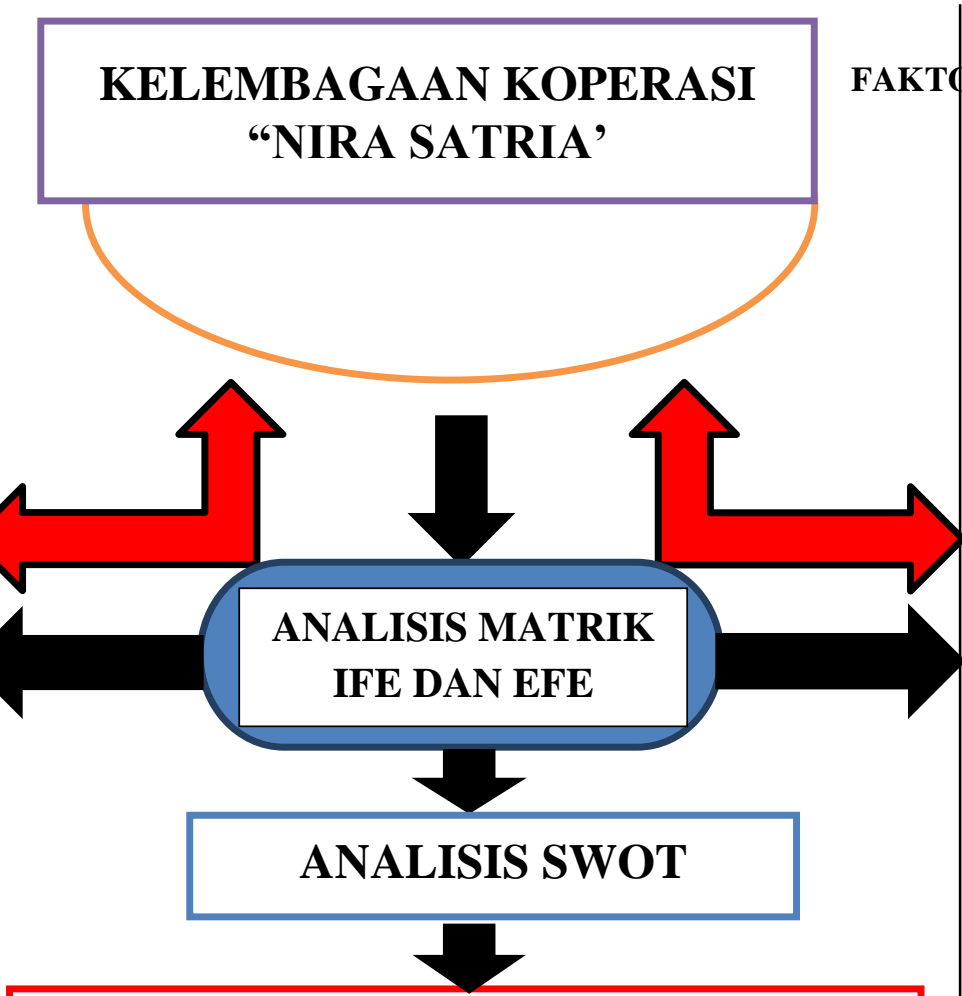

Menciptakan hubungan yang kondusif, demokratis dan kekeluargaan antara pengrajin, manager beserta pengurus koperasi guna mendukung peningkatan kuantitas dan kualitas produk gula kristal sehingga dapat memenuhi permintaan pasar nasional dan internasional secara kontinue $(\mathrm{S} 3,4 ; \mathrm{O} 1,2,3)$.

Memaksimalkan semua unit usaha yang dikelola Koperasi Nira Satria supaya dapat berkembang pesat dengan memanfaatkan teknologi SIM (S5; O6)

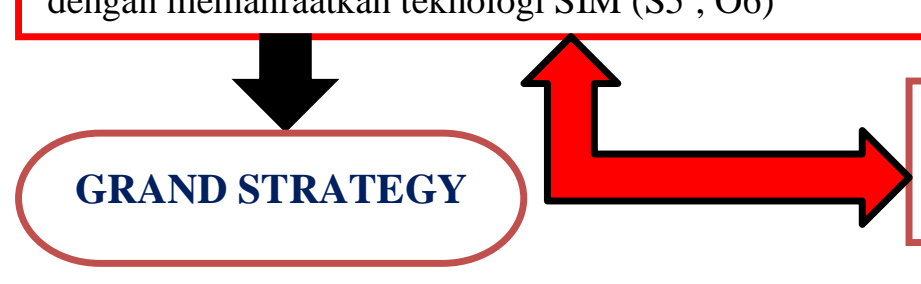

PELUANG

a.Adanya peluang pasar yang prospektif secara nasional atau internasional bagi produk gula kristal

b.Peningkatan konsumsi masyarakat terhadap produk gula kristal

c.Adanya perubahan gaya hidup secara sehat di masyarakat

d.Pembinaan dan pelatihan oleh pihak PEMDA, Disperindag dan instansi terkait kepada pengurus dan anggota Koperasi Nira Satria

e.Tersedianya UU No 12 Tahun 1992 tentang Koperasi

f.Semakin berkembangnya teknologi sistem informasi dan manajemen

\section{ANCAMAN :}

a.Peran tengkulak yang lebih dominan dalam penetapan harga dibanding pengrajin

b.Sikap pengrajin yang masih berhubungan dengan lembaga keuangan non formal di masyarakat sehingga terjerat sistem ijon

c.Masih terbatasnya sarana prasarana sistem informasi dan manajemen di KOPERASI "NIRA SATRIA " 


\section{KESIMPULAN}

1. Faktor internal dan faktor eksternal yang mempengaruhi terhadap kelembagaan Koperasi Nira Satria di Kecamatan Cilongok Kabupaten Banyumas adalah sebagai berikut : Aspek SDA dan SDM, keuangan, usaha/produksi, kelembagaan dan pembinaan Pemda atau instansi setempat, manajemen dan pemasaran

2. Strategi pengembangan kelembagaan Koperasi Nira Satria pengrajin gula kristal dilakukan dengan cara memaksimalkan potensi atau kekuatan yang dimiliki guna meraih peluang secara optimal yang dilakukan dengan Strategi Agresif yaitu Menciptakan hubungan yang kondusif, demokratis dan kekeluargaan antara pengrajin, manager beserta pengurus koperasi guna mendukung peningkatan kuantitas dan kualitas produk gula kristal sehingga dapat memenuhi permintaan pasar nasional dan internasional secara kontinue (S3,4; O1,2,3). Memaksimalkan semua unit usaha yang dikelola Koperasi Nira Satria supaya dapat berkembang pesat dengan memanfaatkan teknologi SIM (S5 ; O6)

\section{SARAN}

Dari hasil penelitian ini nantinya dapat dikembangkan suatu model strategis kelembagaan Koperasi Nira Satria di Kecamatan Cilongok dalam mendukung agroindustri gula kristal yang lebih optimal ditingkat pengrajin skala rumah tangga. Hal ini dapat tercapai dengan memperhatikan faktor internal dan eksternal yang mencakup aspek SDM, teknis, keuangan, teknologi, manajemen dan pemasarannya serta aspek ekonomi, sosial budaya, politik, pemerintahan, hukum sehingga dapat meningkatkan pendapatan sekaligus kesejahteraan keluarga pengrajin gula kristal skala rumah tangga. Kebijakan pada kelembagaan Koperasi Nira Satria perlu diformulasikan model ulang secara lebih terpadu untuk pengembangan agroindustri gula kristal .

\section{DAFTAR PUSTAKA}

Anonim. 2012. Monografi Kecamatan Cilongok. BPP Cilongok. Kabupaten Banyumas.

Anonim. Anonim. 2013. Data Rekapitulasi Home IndustriGula Kelapa Kabupaten Banyumas . Disperindagkop Kab Banyumas.

Budiningsih,Sdan Watemin.2012. Pola Pengembangan Kewirausahaan Petani Pengrajin Gula Kristal. Hasil Penelitian Unggulan Program Studi Agribisnis Fak Pertanian UMP.

David,F.R. 2006. Manajemen Strategi : Konsep . Edisi Sepuluh. Salemba Empat, Jakarta

Kusnandar, Bekti WU dan Sapja A, 2012. Rekayasa Model Aliansi Strategis Agroindustri Skala Kecil (Kasus Kluster Industri Tahu). Jurnal SEPA Vol 9 No 1 September 2012 (74-82)

Miles, M.B dan Huberman,A.M. 1991. Designning Qualitative Research. MacGraw Hill Company, New York.

Syahza A. 2003. Rancangan Model Pemberdayaan Ekonomi Masyarakat Pedesaan Berbasis Agribisnis $\mathrm{d} i$ Daerah Riau. Naskah Dipublikasikan pada Jurnal Pembangunan Pedesaan, 
Budiningsih dan Kusbandiyah’ MODEL STRATEGI KOPERASI

Vol 3 No 2 November. 2003. UNSOED.

Tambunan, Togap. 2006. Kaji Ulang Peran Koperasi dalam Menunjang Ketahanan Pangan. Infokop No 28 Tahun XXII.

Zimmerer, W Thomas, Norman M. Scarborough, 1996. Entrepreneurship and The New Venture Formation. Practice Hall International Inc.New York. 